\title{
Constructivist learning (environments) and how to avoid another tower of Babel: reply to Renkl
}

\author{
David Gijbels · Sofie M. M. Loyens
}

Received: 2 July 2009/Accepted: 3 July 2009

(C) The Author(s) 2009. This article is published with open access at Springerlink.com

First of all, we would like to thank Alexander Renkl for taking the time to read and comment on our special issue on the effects of constructivist learning environments. Such responses indicate that our special issue has been successful in at least one of its goals: It has stimulated further debate about the nature and characteristics of constructivist learning (environments).

We find it difficult to disagree with several of the points made by Renkl (2009), given that we share the same view to a large extent. However, in this commentary we will explain that in our view, there is not necessarily a paradox when constructivists talk about constructivist learning environments. In our opinion, it all depends on how one views and approaches constructivism and we will argue that three perspectives can emerge in this respect: A theory of learning, a philosophical position, and a theory of instruction.

At the same time, we agree that the term "constructivist learning environment" might raise some false expectations. Other labels to refer to what we have called "constructivist learning environments" might be helpful in this respect, e.g., new learning environments or learning environments that foster meaningful learning.

In our introductory article for the special issue, we clearly distinguished between constructivism as a learning theory and educational applications of this theory, i.e., constructivist learning environments (Loyens and Gijbels 2008, pp. 351-352). By making this distinction, we tried to keep theory and pedagogy apart. We concur with Renkl that educational applications such as the use of meaningful problems do not belong to the epistemological core of constructivism. In our view, however, introducing epistemology when discussing constructivism is adding a third perspective besides a theory of learning and a theory of instruction.

D. Gijbels (ه)

University of Antwerp, Antwerp, Belgium

e-mail: david.gijbels@ua.ac.be

S. M. M. Loyens

Erasmus University Rotterdam, Rotterdam, The Netherlands 


\section{Constructivism as a learning theory}

When constructivism is defined as a reaction to the "traditional classroom" or more broadly to cognitivism, it is viewed as a learning theory, since it concentrates on the question "How do learners acquire knowledge?" Constructivism is a learning theory that is student-centered, since the emphasis is on students as active learners. Although most cognitive views on learning would agree with the concept of "active learners", constructivism lays more emphasis on learners constructing their own understanding. In this respect, constructivism could also be considered as a rising paradigm in the field of cognitive psychology instead of a reaction against it.

\section{Constructivism as a philosophical position}

Others see constructivism as a philosophical position, grounded in epistemology and focused on the discussion about what knowledge really is. Colliver (2002, p. 51), for example, prefers to see constructivism as "an insight into the nature of human knowledge". Constructivism is not a theory of learning, according to him, because regardless of whether we think of knowledge as a construction process or a representation of reality the principles of learning are the same. Saunders states that "constructivism can be defined as a philosophical position which holds that any so-called reality is, in the most immediate and concrete sense, the mental construction of those who believe they have discovered and investigated it" (Saunders 1992, p. 136).

\section{Constructivism as a theory of instruction}

A third perspective on constructivism is instructional, pedagogical. According to this view, constructivism is a theory of instruction that situates itself on the "prescriptive level" as Renkl puts it, making claims about what the classroom or more broadly, instruction should look like.

\section{Constructivists talking about constructivist learning environments is not a paradox}

As mentioned above, we do not concur with this view, because we believe this view mixes up theory and pedagogy. However, we do believe that from constructivism as a learning theory (i.e., the descriptive level), implications can be drawn for educational practice. Therefore, for the sake of conceptual clarity, we would define constructivism as a theory about how we learn, grounded in philosophy with implications for instruction. All three elements (learning theory, philosophical position and instruction) are incorporated in this definition and we hope it became clear from the previous paragraphs that the perspective in which one approaches constructivism is crucial. For this reason, we do not regard it as a paradox that constructivists talk about constructivist learning environments, since they are focusing on the implications of a learning theory. 


\section{Meaningful learning is also possible outside constructivist learning environments}

In addition, we do not believe that meaningful learning is impossible outside learning environments that are labeled as "constructivist". We acknowledge that learning in lectures can be a constructive process, leading to meaningful learning. We do not claim that meaningful learning exclusively occurs in a learning environment that is designed explicitly based on constructivist theories of learning. Again, when we talk about constructivist learning environments that is exactly what we refer to: the application in educational practice of constructivist theories of learning.

\section{Should the c-word be banned?}

In our special issue, we already discussed the notion of "new learning environments" to point to this and to "refer to learning environments that intend to develop an educational setting to meet the challenge for today's higher education, making the students' learning the core issue and defining instruction as enhancing the learning process (...) these new learning environments are mainly (but not exclusively) rooted in constructivist theory and claim to have the potential to improve the educational outcomes for students in higher education" (Loyens and Gijbels 2008, p. 353). Some of the papers in our special issue were related to such learning environments consisting of a mix of educational methods (including lectures) designed mainly based on constructivist theories of learning with the intention to induce meaningful learning activities. Although we state that talking about "constructivist learning environments" is not a paradox, we do agree that there are some clear disadvantages that might argue for not using this term. One of these disadvantages is that the term can create false expectations on a "prescriptive level". We agree with the claim that one "cannot directly deduce from the basic constructivist assumptions of active sense-making and knowledge construction that so-called "constructivist" learning environments are superior to arrangements that are usually regarded as "traditional". What one can conclude is that in any type of (meaningful) learning environment, instruction should be designed in such a way that there is a high probability students will engage in active sense-making and knowledge construction" (Renkl 2009).

When talking about "effects of constructivist learning environments" and defining them as learning environments that "contain several features that are believed to promote effective learning (Loyens and Gijbels 2008, p. 352)" this might suggest that we see socalled constructivist learning environments as superior. Prior research that compared traditional learning environments with more constructivist learning environments (e.g., Gijbels et al. 2005; Loyens et al. 2006) probably strengthens this view. However, this was not the intention of the special issue. In the special issue we wanted to go a step further by looking to what happens in so-called constructivist learning environments. From the papers included in the special issue, it should be clear that we encourage research that looks at a wide range of effects in a wide range of learning environments, including those "traditional learning environments" designed to induce meaningful learning activities in the students. In this perspective some of the authors in our special issue used the concept of new learning environments rather than constructivist learning environment (e.g., Harris et al. 2008; Hmelo-Silver et al. 2008). The link with the theory of constructivism is less straightforward using the term "new" and it seems to be more appropriate for the kind of learning environments and the kind of research questions that we advocate. We agree again with Renkl (2009) that research should focus on "how to best induce active-sense-making 
and knowledge construction, irrespective whether the chosen learning environment is usually regarded as a "traditional" or a "constructivist" arrangement".

Open Access This article is distributed under the terms of the Creative Commons Attribution Noncommercial License which permits any noncommercial use, distribution, and reproduction in any medium, provided the original author(s) and source are credited.

\section{References}

Colliver, J. A. (2002). Constructivism: The view of knowledge that ended philosophy or a theory of learning and instruction? Teaching and Learning in Medicine, 14, 49-51.

Gijbels, D., Dochy, F., Van den Bossche, P., \& Segers, M. (2005). Effects of problem-based learning: A meta-analysis from the angle of assessment. Review of Educational Research, 75, $27-61$.

Harris, K. R., Santagelo, T., \& Graham, S. (2008). Self-regulated strategy development in writing: Going beyond NLEs to a more balanced approach. Instructional Science, 36, 395-408.

Hmelo-Silver, C. E., Chernobilsky, E., \& Jordan, E. (2008). Understanding collaborative learning processes in new learning environments. Instructional Science, 36, 409-430.

Loyens, S. M. M., \& Gijbels, D. (2008). Understanding the effects of constructivist learning environments: Introducing a multi-directional approach. Instructional Science, 36, 351-357.

Loyens, S. M. M., Rikers, R. M. J. P., \& Schmidt, H. G. (2006). Students' conceptions of constructivist learning: A comparison between a traditional and a problem-based learning curriculum. Advances in Health Sciences Education, 11, 365-379.

Renkl, A. (2009). Why constructivists should not talk about constructivist learning environments. A commentary on Loyens and Gijbels (2008). Instructional Science. doi: 10.1007/s11251-009-9098-5

Saunders, W. L. (1992). The constructivist perspective: Implications and teaching strategies for science. School Science and Mathematics, 92, 136-141. 